\title{
APPLICATION OF MULTICHANNEL ANALYSIS OF SURFACE WAVES METHOD (MASW) IN AN AREA SUSCEPTIBLE TO LANDSLIDE AT UBATUBA CITY, BRAZIL
}

\author{
Sérgio Bezerra Lima Júnior ${ }^{1}$, Renato Luiz Prado² and Rodolfo Moreda Mendes ${ }^{3}$ \\ Recebido em 14 outubro, 2011 / Aceito em 3 abril, 2012 \\ Received on October 14, 2011 / Accepted on April 3, 2012
}

\begin{abstract}
This paper presents results from the MASW method (multichannel analysis of surface waves) in a hill side area of unsaturated soils in the Ubatuba City, Brazil, a site where numerous mass movements have occurred. It discusses the influence of some acquisition parameters, such as, the natural frequency of geophones and minimum and maximum offsets in dispersion image results and does a comparative analysis of the results obtained in repeated tests carried out in the same place, under the same conditions, during the dry and rainy seasons. The comparative analysis for the inversion results in different periods showed that the values of S-wave velocity during the dry season were higher than those for the rainy season; these variations were attributed to the higher cohesion of the soil structure in the dry season. The final 1D velocity profile model with depth was consistent with the results of other geophysical and geotechnical investigations made. Although additional in situ and laboratory geotechnical tests, are necessary (to obtain soil parameters such as hydraulic conductivity, moisture content, soil suction, for example), for a complete characterization of the geotechnical properties of the investigated soil, the result shows that it is possible to use empirical correlations between the Vs profile, from the MASW method, and soil stiffness parameters in order to monitor areas susceptible to landslide.
\end{abstract}

Keywords: MASW, Rayleigh waves, seismic methods, unsaturated soils, dynamic shear modulus.

RESUMO. Este trabalho apresenta resultados da aplicação do método MASW (multichanne/ analysis of surface waves) em uma área de encosta com solos não saturados, no município de Ubatuba, Estado de São Paulo, onde ocorrem numerosos movimentos de massa. Discute a influência de alguns dos parâmetros de aquisição (frequência dos geofones e afastamentos), no resultado da imagem de dispersão, além de fazer uma análise comparativa dos resultados obtidos em ensaios repetidos no mesmo local e sob as mesmas condições, em dois períodos do ano (seco e úmido). A análise comparativa entre os resultados das inversões nos distintos períodos mostrou que os valores de velocidade da onda S (Vs) do período mais seco foram superiores aos do período das chuvas; variações atribuídas ao aumento das tensões capilares e da coesão entre os grãos da estrutura do solo. 0 modelo final 1D de velocidades com a profundidade é coerente com os obtidos em outras investigações geofísicas e geotécnicas feitas no local. Embora sejam necessários ensaios geotécnicos adicionais, in situ e em laboratório (para obtenção de parâmetros como condutividade hidráulica, teor de umidade, medição da sucção, por exemplo), para uma completa caracterização das propriedades geotécnicas do maciço investigado, o resultado apresentado mostra ser possível usar correlações empíricas sítios-dependentes entre Vs, obtidos através do método MASW, e parâmetros de resistência do solo para subsidiar projetos de monitoramento de áreas de instabilidade.

Palavras-chave: MASW, ondas Rayleigh, métodos sísmicos, solos não saturados, módulo de cisalhamento dinâmico.

\footnotetext{
${ }^{1}$ Laboratório de Geofísica de Prospecção e Sensoriamento Remoto (LGPSR), Departamento de Geologia, Universidade Federal do Ceará, Campus Universitário do PICI, Bloco 913, 60455-760 Fortaleza, CE, Brazil. Phone/Fax: +55 (85) 3366-9870 - E-mail: sergioblj@gmail.com

2 Instituto de Astronomia, Geofísica e Ciências Atmosféricas, Universidade de São Paulo, Rua do Matão, 1226, Cidade Universitária, 05508-090 São Paulo, SP, Brazil. Phone: +55 (11) 3091-2762; Fax: +55 (11) 3091-5034 - E-mail: renato@iag.usp.br

3 Instituto Geológico do Estado de São Paulo, Avenida Miguel Stéfano, 3900, Água Funda, Caixa Postal 8772, 04301-903 São Paulo, SP, Brazil. Phone: +55 (11) 5058-9994 Extension: 2047; Fax: +55 (11) 5073-5511 - E-mail: rodolfommendes@ig.com.br
} 


\section{INTRODUCTION}

The knowledge of the elastic properties of the geological materials through the analysis of the seismic waves propagation has great importance in the geotechnical engineering and engineering geology. The records of the seismic waves allow the obtaining of the dynamic elastic moduli and empiric correlations with geotechnical parameters (Barton et al., 1974; Turk \& Dearman, 1987; Giacheti, 1991; Prado, 1994). Concerning the surface materials, the study of the shear wave (S-wave) is more interesting for soil mechanics and foundation engineering. The importance comes from the fact that the S-wave velocity is directly related to the resistance of the soil structure through which the wave propagates. The dynamic shear modulus obtained from the S-wave velocities and from the densities of the materials is one of the main parameters used to predict the tension-deformation behavior of the soils subjected to dynamic loads, which means deformation at low strain level.

Among the seismic methods applied with this purpose, the crosshole survey is the one that stands out, due to its precision and resolution. On the other hand, it is a time-consuming essay and with a relatively high cost, since it requires at least two drilling holes properly cased and specially prepared for the survey. In addition, the shallow refraction seismic with S-waves has been used (Goforth \& Hayward, 1992), but it is more difficult to achieve a reasonable degree of accuracy in the S-wave identification.

The seismic methods that use the surface waves (mainly Rayleigh waves) have also been used for obtaining the S-wave velocity (Vs) profile. Initially, only two receivers were used (Nazarian \& Stokoe, 1984), but it evolved to the use of multiple geophones (Park et al., 1999; Foti, 2000).

In Brazil, the method is not well known but it already was the object of academic studies. Marchioreto (2002) used the SASW (spectral analysis of surface waves) technique, that employs only two receivers, and Lima Júnior (2007) the multichannel method, known as MASW (multichannel analysis of surface waves).

Although in the international scenario its use has significantly increased in the last ten years, as well as the publications presenting study cases and discussions about methodological aspects, there are not standard procedures regarding the adoption of the acquisition parameters.

This paper presents results obtained using the MASW method on a hillside area with unsaturated soils, in the Ubatuba City, Brazil, a site where mass movements have occurred.

The purpose of the work was to evaluate the influence of acquisition parameters, such as natural frequency of the geophones and minimum and maximum offsets, in dispersion image results, and to make a comparative analysis of the results, for the same site, obtained in repeated tests, under the same conditions, during the dry and rainy seasons.

This last objective aimed to understand the conditions related to the slope instability in the area, intensified during the rainy season, which are attributed to the development of pore-water pressures originated by the rainfall infiltration (Vargas, 1999).

Considering that the shearing strength of the unsaturated superficial soils is, among other factors, strongly influenced by the matrix suction, which results from the capillarity forces and adsorption, originated by the interaction between the soil matrix and water (Cintra, 2004), would the intermittent monitoring of the Vs, through the Rayleigh waves method, be of any help for evaluating the slope stability?

The results of this work indicated variations in the velocity profiles obtained in different periods. Although it is known that more detailed investigations are necessary for a good characterization of the geotechnical properties of the studied soils, it is believed that the differences that were verified are associated to the cohesion alterations among the soil grains and the shear strength due to variations of the capillary tensions. These types of analysis can be an auxiliary tool for slope stability studies.

\section{STUDY AREA}

The study area is located in the Maranduba beach (Latitude $23^{\circ} 32^{\prime} 09^{\prime \prime} \mathrm{S}$ and longitude $45^{\circ} 14^{\prime} 10^{\prime \prime} \mathrm{W}$ ), in the municipal district of Ubatuba, northern coast of the São Paulo State (Fig. 1). The site is located at mid-slope of an isolated hill, with average declivities from 15 to $20 \%$, local amplitudes of 100 meters with convex to straight slopes.

It is an abandoned mining area of residual soil under advanced stage of environmental degradation. It is geologically characterized by the presence of homogeneous migmatites with brecciated and nebulitic structures conferring a granite-gneissic geotechnical characteristic to the regolith.

In general, the area presents a humid tropical climate, with high temperatures (average of $25.5^{\circ} \mathrm{C}$ ) along the whole year, small thermal amplitude and average annual rainfall above 2,000 mm. The highest rainfall occurs during the summer, usually with larger concentration in January. Figure 2 shows a typical weathering profile, obtained from field visual inspection and from disturbed and undisturbed soil samples collected along the hill slope (Mendes, 2008).

\section{METHODOLOGY Data acquisition}

MASW acquisition methodology follows the configuration usually employed for refraction seismic surveys, in other words, a linear 


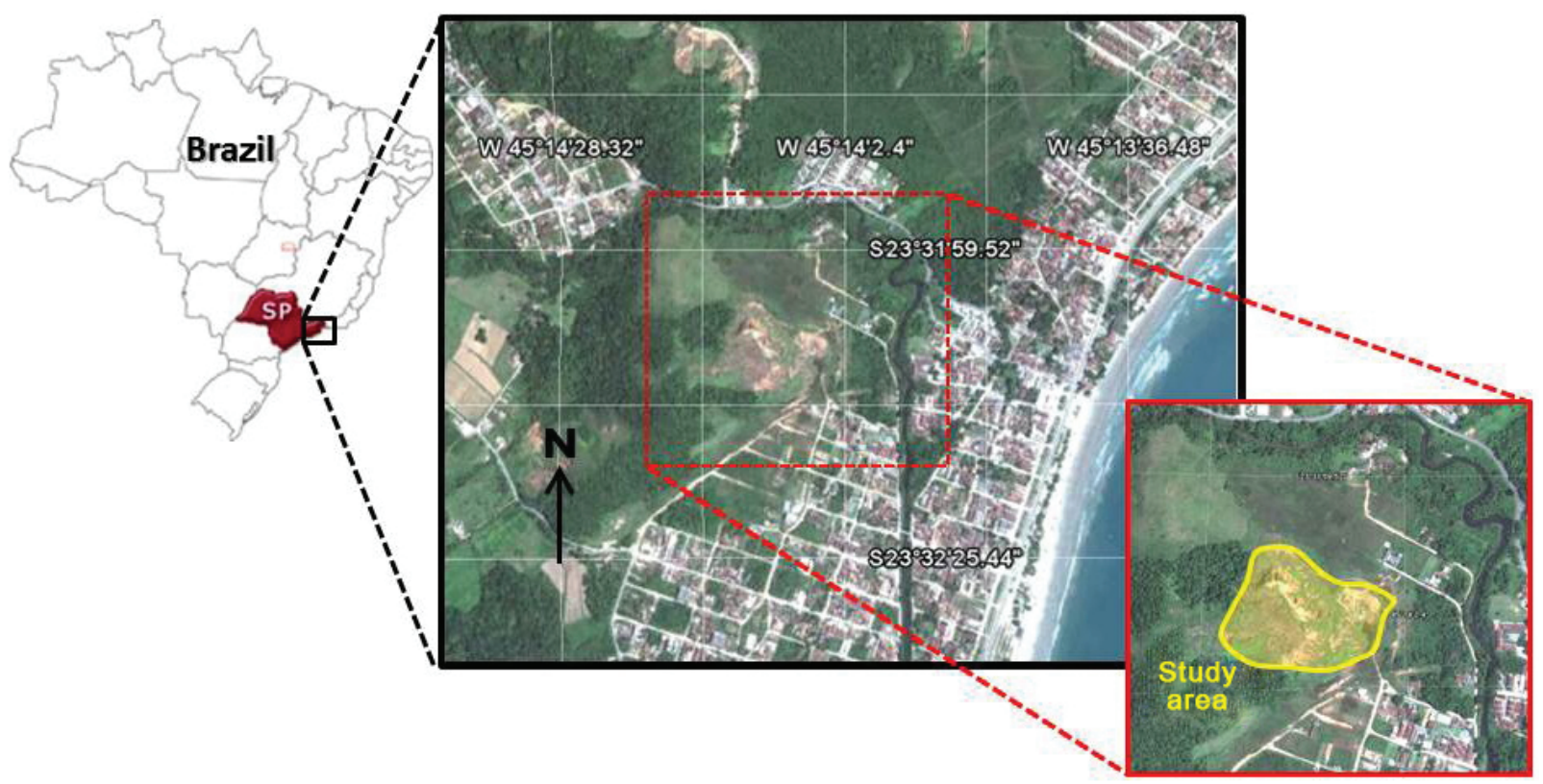

Figure 1 - Study area situated at Maranduba beach, Ubatuba City, São Paulo State, Brazil. Source: Google Earth, 2010.

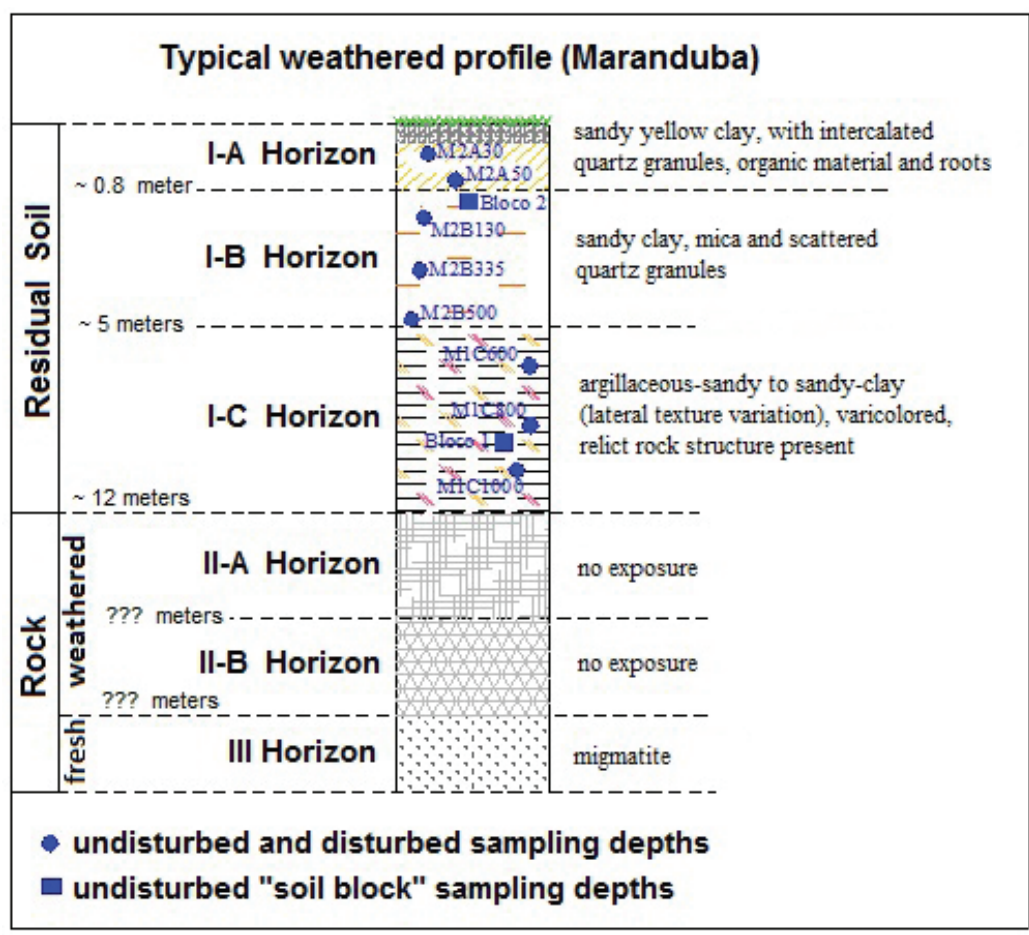

Figure 2 - Typical weathered profile from the surveyed site (modified by Mendes, 2008).

array of vertical component geophones and the source. Usually the acquisition parameters are from one to two seconds of time window at a sample rate of one millisecond.

The acquisitions occurred in two different surveys during the year. The first campaign was carried out in April/2006, at the end of the rainy season, and the second in August/2006, at the end of the dry season.

Three 24-channel Geode (Geometrics Inc.) seismographs were used each one with a group of geophones of different natural frequencies ( $4.5 \mathrm{~Hz}, 14 \mathrm{~Hz}$ and $28 \mathrm{~Hz}$ ), with simultaneous 


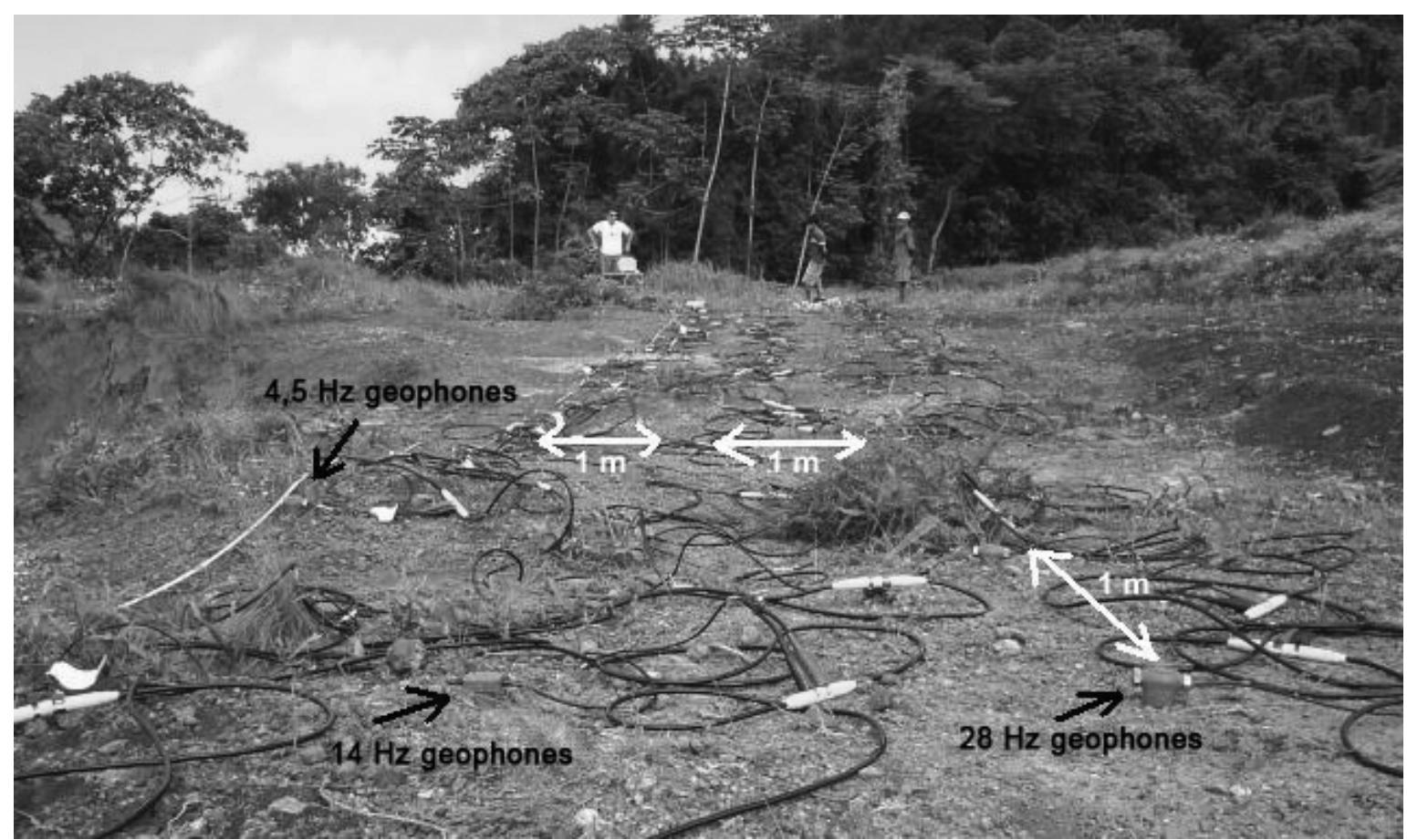

Figure 3 - Surveyed site, showing the adopted geophone configuration.

recordings at each shot. Each group of geophones of the same frequency formed a linear array. The in-line geophones spacing was 1 meter and each group were side by side 1 meter apart (Fig. 3).

The seismic source was the impact of a hammer, with approximately 8 kilograms, on a metallic plate with a diameter of 25 centimeters. Different minimum offsets were tested, from one up to 15 meters.

The purpose of using different minimum offsets and geophone frequencies was to establish comparisons among the dispersion curves obtained aiming to define the ideal acquisition parameters for the site.

The spacing among geophones and the length of the adopted array defined the minimum and maximum theoretical depth that could be investigated. The penetration depth of the surface wave is approximately equivalent to its wavelength, but the method allows subsurface mapping up to approximately half of the registered wavelength (Park et al., 1999).

\section{Data processing}

The standard processing consists of extracting from the seismograms the dispersive characteristics of the Rayleigh waves, that is, the phase velocities in function of the frequencies. The dispersion image shows the fundamental and upper modes of the
Rayleigh wave (Aki \& Richards, 1980). The dispersion curves are obtained after searching the maxima of energy density observed in the image. It is usually assumed, in shallow applications, that the fundamental mode is the dominant energy. Upon extraction of the dispersion curve, the next step is to proceed to the inversion process for obtaining the velocities model (Fig. 4).

The Surfseis software, used in this processing, employs the procedure proposed by Park et al. (1999), and consists initially in the transformation of the wavefield recorded by the field data into the dispersion image.

Seismograms are firstly converted from the time domain to the frequency domain through the FFT (Fast Fourier Transform). The transformed seismic trace, $R_{i}(x, \omega)$, may be represented by the multiplication of their amplitude spectra $\left(A_{i}\right)$ and phase $\left(P_{i}\right)$ :

$$
R_{i}(x, \omega)=A_{i}(x, \omega) P_{i}(x, \omega)(1)
$$

where $x=$ offset and $\omega=$ frequency. A new integral transformation of $R_{i}(x, \omega)$ leads to $V(\omega, \varphi)$ :

$$
V(\omega, \varphi)=\int e^{i \varphi x}[R(x, \omega) /|R(x, \omega)|] d x
$$

Integral (2) represents the sum of the amplitude values in each offset $(x)$ for each considered frequency. The sum is performed after the application of a phase shift $(\varphi)$ dependent of the offset, and repeated for each one of the values of the considered 


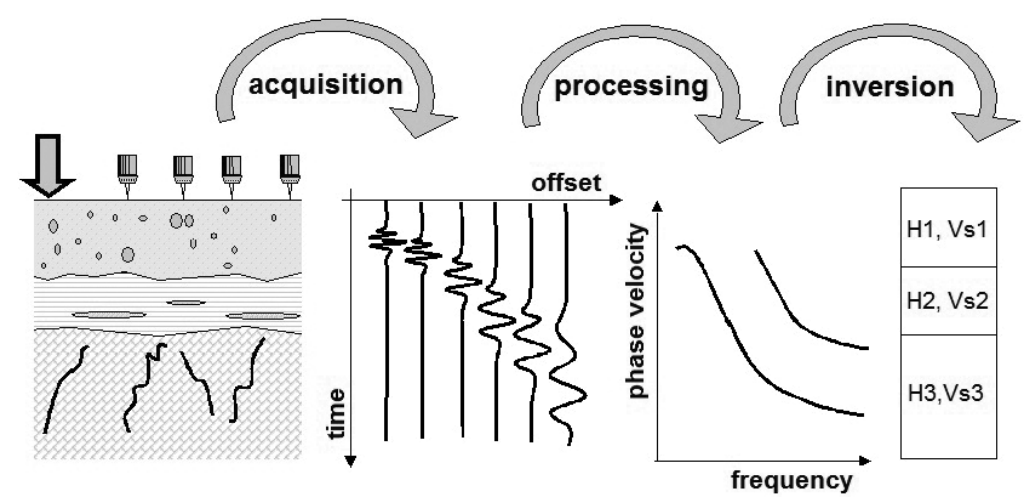

Figure 4 - Illustration of the different phases of the method for surface waves analysis: data acquisition, extraction of information about surface waves dispersion (processing) and inversion for obtaining the subsurface velocities model (adapted from Strobbia, 2002).

phase velocities. The calculated absolute values are plotted after the transformation of $V(\omega, \varphi)$ into $I(\omega, c)$ through the change of variables, considering $c=\omega / \varphi$. The dispersion curves represent the maxima of energy for each frequency present in this domain.

When the dispersion curve is extracted, inversion processes are used to infer a layer's model based on the velocities of the shear waves (S).

The phase velocity of the Rayleigh wave is a function of four Earth's parameters: the S-wave velocity, the P-wave velocity, the layer's density and thickness, and frequency. Xia et al. (1999) have showed through sensitivity tests, using multiple layer models, that each parameter contributes in the dispersion curve in an exclusive way, but the velocity variations of the $S$-waves exert more significant influence to the phase velocities of the Rayleigh wave. Thus, the assumption of the inversion algorithm (Xia et al., 1999) is that the velocities of the S-waves are the ones that fundamentally control the changes in the velocities of the Rayleigh wave in stratified models. Therefore they may be appropriately obtained from the inversion of the phase velocities of the Rayleigh wave (Fig. 4). The numeric method used by the Surfseis for the inversion process is described in Xia et al. (1999).

\section{Data analysis}

Once data with different minimum offsets and geophones with distinct natural frequencies were acquired, an initial analysis of the entire data set was performed aiming the choice of the record with the best signal/noise ratio. In this particular case, signal refers to the groundroll event.

Regarding the signal/noise ratio, the choice of the field geometry is directly related to the near-field and far-offset effects; the first case is related to the required minimum offset to provide that the Rayleigh wave, when arriving to the geophones, may be considered as a horizontally travelling plane wave (Richart et al., 1970); the second case, is related to the maximum possible offset in order to avoid the high frequency component of the body wave surpassing the one of the surface wave. There are several propositions to determine the acquisition geometry (Stokoe et al., 1994; Park et al., 1999; Zhang et al., 2004; Xu et al., 2006; Bodet et al., 2009; Yoon \& Rix, 2009; Dikmen et al., 2010), based on empiric or on analytical studies of the wave paths or in modeling, that are, at times, contradictory. Park et al. (1999), for instance, suggest that the employed offsets should be larger than half of the maximum desired wavelength which, therefore, depends on the geological objective to be investigated. However, there is a prevailing practice of adopting the minimum offset equal to the adopted geophone interval, to facilitate the acquisition of long seismic lines and to implement automatic processing flowcharts (Bodet et al., 2009). Hence, the reason to execute, in this study, the field configuration tests.

The use of different natural frequency geophones, as already mentioned, was aimed to obtain the most wide frequency response.

Even with the use of a small-mass source (sledgehammer), and under the conditions of the investigated area (structured saprolitic soil), the comparative analysis of the amplitude spectra showed the $4.5 \mathrm{~Hz}$ geophone to be the most suitable (Fig. 5), because it presented the highest energies for low frequencies (up to approximately $40 \mathrm{~Hz}$ ), propitiating the deepest investigation.

Besides the evaluation of the amplitude spectra of the data acquired with different offsets, it was also carried out the analysis of some field data transformed into swept-frequency records, as suggested by Park et al. (1999). 


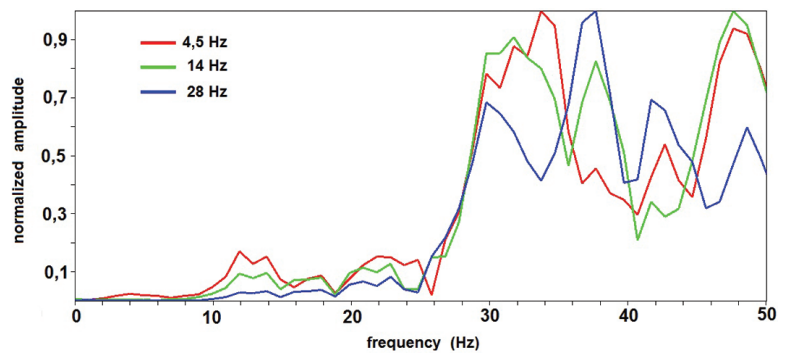

Figure 5 - Amplitude spectra for records obtained with $4.5 \mathrm{~Hz}$ (red line), $14 \mathrm{~Hz}$ (green line), $28 \mathrm{~Hz}$ (blue line) geophones, minimum offset of 4 meters.

This data transformation adds expressive help for the identification of the far-offset effect through the analysis of phase's linear coherence for the entire offset interval. It also contributes for the choice of the maximum offset for obtaining the dispersion curve.

An impulsive record $r(t)$ obtained using the hammer as the source can be transformed into a swept-frequency record, $r_{s}(t)$, by convolution of $r(t)$ with a sinusoidal function with time-variant frequency, similar to those used in surveys with Vibroseis sources (Park et al., 1999). Thus, it follows:

$$
r_{s}(t)=r(t) * s(t)
$$

being $s(t)$ of the form:

$$
s(t)=\operatorname{sen}\left(2 \pi f_{1} t+\frac{\pi\left(f_{2}-f_{1}\right) t^{2}}{T}\right)
$$

where $f_{1}, f_{2}$ are the lowest and highest frequencies, and $T$ the record length of $s(t)$.

Figure 6 presents the transformed data, recorded with 1 meter, 4 meters and 10 meters minimum offsets, and $4.5 \mathrm{~Hz}$ geophones.

It may be observed in Figure 6, that for the analyzed frequency range, the records obtained with minimum offsets, of 1 and 4 meters, present similar behavior, with good phase coherence up to the intermediate frequencies $(<40 \mathrm{~Hz})$, and with some coherence loss in the highest frequencies. However, for records with 10 meters minimum offset, in general, coherence is low.

Following this criterion, analysis should be restricted to seismograms with maximum offsets up to approximately 30 meters, and even so in frequencies above $40 \mathrm{~Hz}$ one should expect more interference of the energy of the body waves in the dispersion curve.

In the comparative analysis of the dispersion images (phase velocity-frequency domain), generated from field data acquired with different minimum offsets, it was observed that as the offsets got larger, energies related with the higher mode surface waves, became more important and began to interfere with the fundamental mode (Fig. 7).

Since the inversion is carried out considering the fundamental mode, also for this criterion the use of records with smaller minimum offsets were considered more appropriate.

Figure 8 presents all dispersion curves extracted from data obtained in April/2006 with different minimum offsets (1 to 15 meters). Similar tendency can be observed for all dispersion curves, with some deviations attributed to experimental errors during data acquisition. However, those curves associated to the smallest and largest minimum offset used (represented in Fig. 8 by blue and yellow squares, respectively), in general, restrict the minimum and maximum values of the phase velocities for the lower frequency range, in other words, as the maximum offset is increased, an apparent increase of the higher phase velocities associated to the deeper horizons is observed.

After a joint analysis of all previously described aspects, we have decided to conduct the final processing and inversion only for data recorded with geophones of $4.5 \mathrm{~Hz}$ natural frequency, and with minimum offsets of 4, 5 and 6 meters (red dispersion curves of Fig. 8).

Low frequency geophones $(4.5 \mathrm{~Hz})$ acted as analog filters, recording the lower frequency components of surface waves effectively. The minimum offsets chosen represented the best configuration to avoid the undesirable effects of near- and far-offset, allowing a better recognition of the fundamental mode of the surface wave in the dispersion image.

Upon definition of those criteria, a mute filter was applied to eliminate the refracted P-waves, and a low-pass frequency filter $(50-60 \mathrm{~Hz})$ was used seeking a decrease of the body waves interference on the surface waves. Afterwards, using the Surfseis software, a dispersion image of each one of the records was obtained.

Still seeking the improvement of the signal/noise ratio, the dispersion images generated from each seismogram were stacked before the extraction of the fundamental mode dispersion curve. The dispersion curve used for the inversion was limited to the frequency range up to approximately $20 \mathrm{~Hz}$, where the fundamental mode was better identified.

Then, two stacked dispersion images were obtained: one for data collected in April/2006, and the other for data collected, with the same configurations, in August/2006 (Fig. 9).

An initial model based on the extracted dispersion curve is generated in the inversion process. A 10-layer model is generated with thicknesses increasing with depth, whose maximum depth is determined by the longest wavelength calculated from 

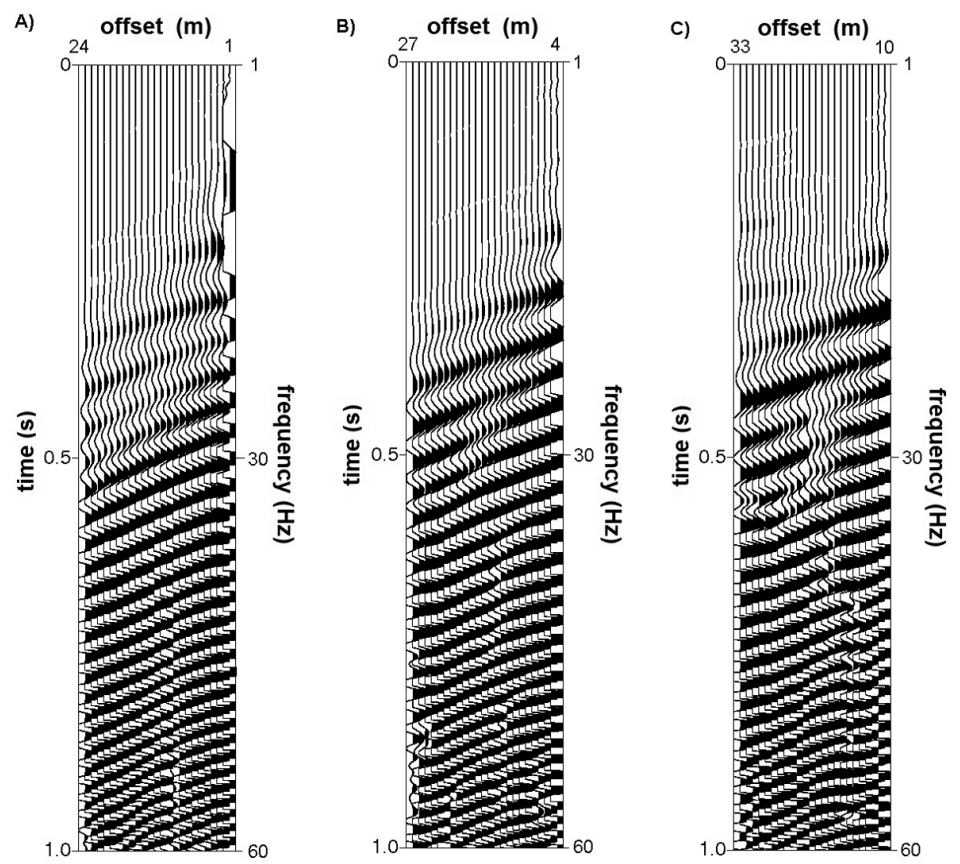

Figure 6 - Field records transformed for the swept-frequency domain. Recorded (A) with minimum offset of 1 meter, (B) minimum offset of 4 meters, and (C) minimum offset of 10 meters.

the dispersion curve (based on the values of the phase velocityfrequency pairs). The velocities of the S-waves for each layer are inferred from the phase velocities of the dispersion curve and from the Poisson's coefficient (assumed, in shallow investigations, as 0.4).

Several iterations are accomplished with successive adjustments to the model. The process is concluded for the criterion of minimum root mean square error (RMS) among the values of the theoretical dispersion curve (obtained from the initial model), and from the observed dispersion curve (extracted from the dispersion image), or when reaching the desired number of iterations.

\section{DISCUSSIONS}

Seeking a comparison of the results obtained for the two different periods, analysis of the S-wave velocity profile was restricted to the shallowest segment, related with the soil horizons that are under a larger influence of the rainfall infiltration.

In this case, from the velocity profiles shown in Figures $9 \mathrm{C}$ and $D$, two interfaces are inferred at depths of approximately 2 and 5 meters.

Figure 10 presents the S-wave velocity profiles for the most superficial horizons obtained with the inversion of the dispersion curves (Fig. 9). The profiles obtained for the two periods are different in terms of values, but present the same tendency varia- tion at depth. The Vs values in the dry season (August/2006) are systematically higher than those of the rainy season (April/2006).

The explanation for this fact may be an increase of the matrix suction in the driest season. Under low moisture content conditions, approximately between 5\% and 20\% (Wu et al., 1984), the matrix suction increases the contact among the grains of the soil structure, resulting in an increase in the cohesion and, consequently increasing shear strength, inducing a direct relation with the S-wave propagation velocity.

Results of GPR (Ground Penetrating Radar) surveys carried out at the same place (Figs. 11 and 12) corroborate with the interpretation of the two interfaces. GPR data were collected in August/2005 (dry season) and March/2006 (rainy season) with $200 \mathrm{MHz}$ antennas using the CMP (common mid point) array. Figure 11 presents the results for velocity analyses of the radargrams using the velocity spectrum (semblance function). The profiles (Fig. 12), with depth restricted to the first five meters, show that the velocity values of the electromagnetic wave in the superficial horizons are lower in the humid periods (March); in coherence with the expected increase of the soil moisture content.

\section{FINAL COMMENTS}

The choice of the minimum and maximum offsets during the surface waves essays exerts a great influence in the result of the dispersion image and, consequently, in the inversion result. 
A)

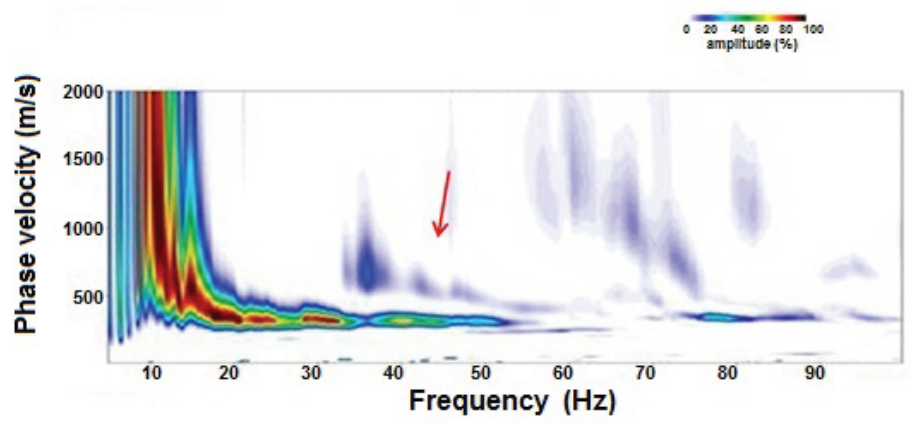

B)

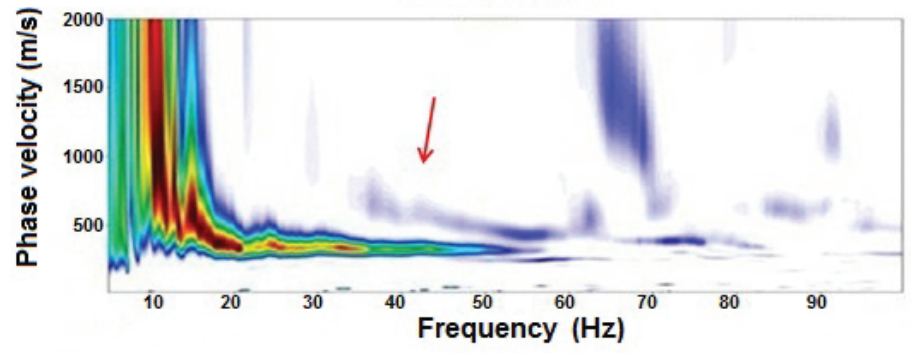

C)

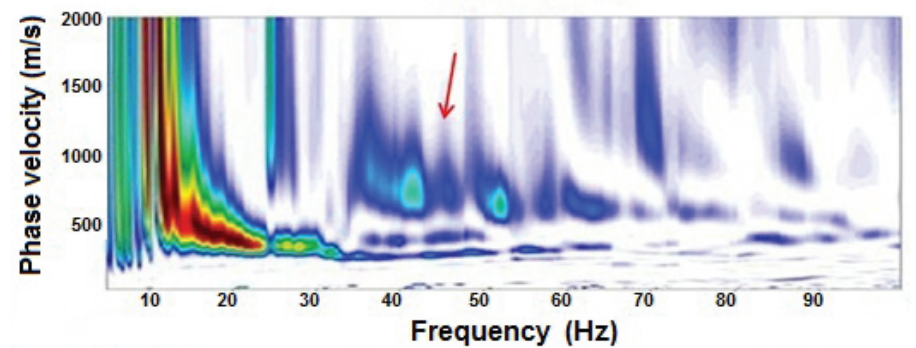

D)

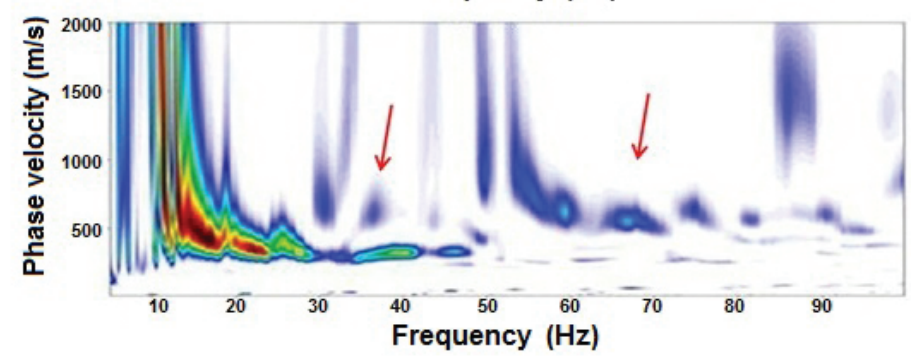

Figure 7 - Dispersion images generated from seismic records obtained using minimum offsets of 1 (A), 4 (B), $9(\mathrm{C})$ and 15 meters (D). Red arrows indicate the upper modes.

Low-resolution images hamper the differentiations among the surface wave modes due to the effects of near- and far-offset. The offset parameter keeps a close relationship with the characteristics of the site under investigation, and for this reason it is suggested the use of an initial test (similar to the walkaway test performed by shallow reflection seismic) in order to record the seismograms using different minimum offsets. The transformations of the seismograms obtained by an impulsive source as the sledgehammer into the swept-frequency record are extremely helpful to evaluate the effects of the near- and far-offset. Panels with the dispersion images generated from data acquired with different offsets also help the definition of the best acquisition parameters.
The lower frequency $(4.5 \mathrm{~Hz})$ geophones were the ones that recorded the broader spectral bandwidth, which helps the identification of the fundamental mode of the Rayleigh waves after the seismogram transformation.

The observed velocity variations, both for the S-wave and the electromagnetic wave, in different seasons, suggest a connection with variations of the soil moisture content. Thus, the Vs increased values verified in the driest season should be related with the increase of the matrix suction of the soil, resulting in an increase of its shearing strength and apparent cohesion.

Although more detailed geologic-geotechnical studies are required for a good characterization of the geotechnical properties of 


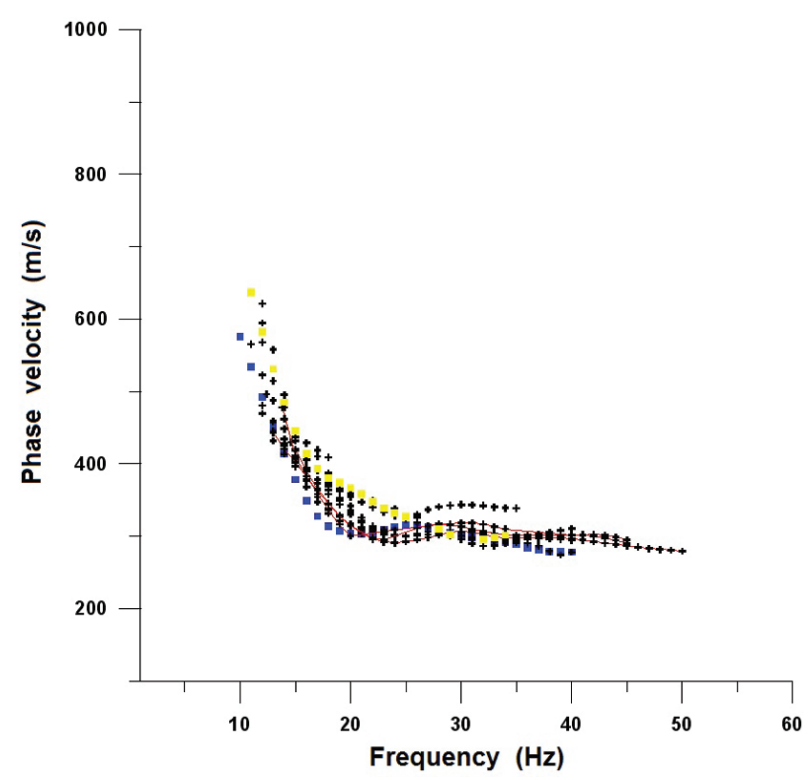

Figure 8 - Dispersion curves for minimum offsets from 1 to 15 meters (data from April/2006). Blue squares represent curve points referring to data acquired with minimum offset of 1 meter (lower), yellow squares represent data acquired with minimum offset of 15 meters (upper), red lines refer to data with minimum offsets of 4, 5 and 6 meters.
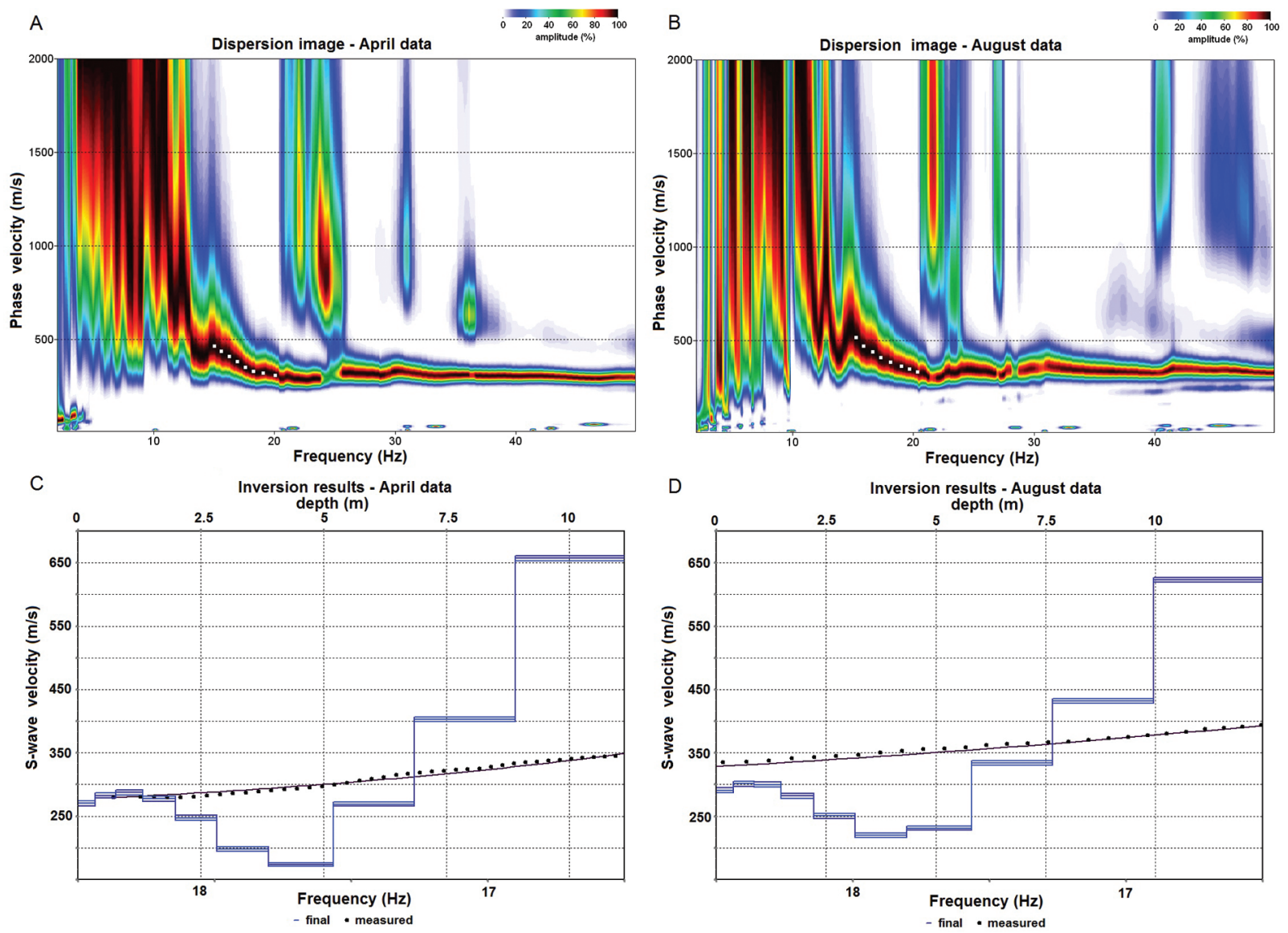

Figure 9 - Dispersion images ( $A$ and $B$ ) with the curves extracted for inversion (white dots), and the respective velocity models ( $C$ and $D)$, (with RMS error range) obtained with the inversion process. Figures $9(\mathrm{C}$ and $\mathrm{D})$ also show the measured dispersion curves and the inversion final adjustment. 


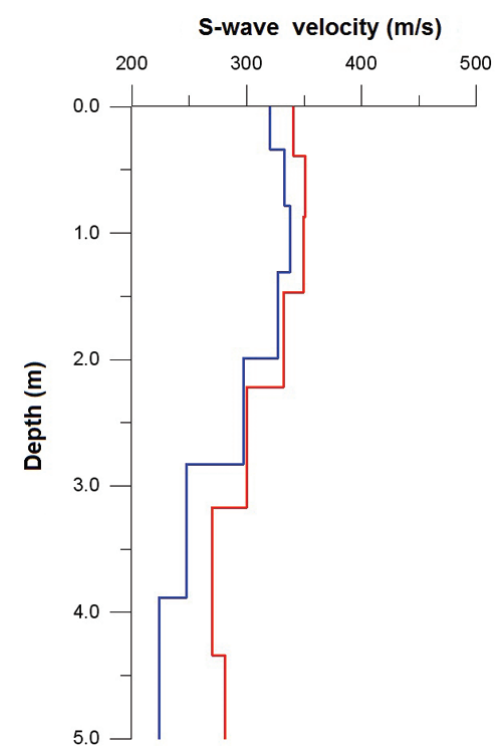

Figure 10 - S-wave velocity profiles obtained from the dispersion curves of the surface waves, for data from April/2006 (blue line) and August/2006 (red line).
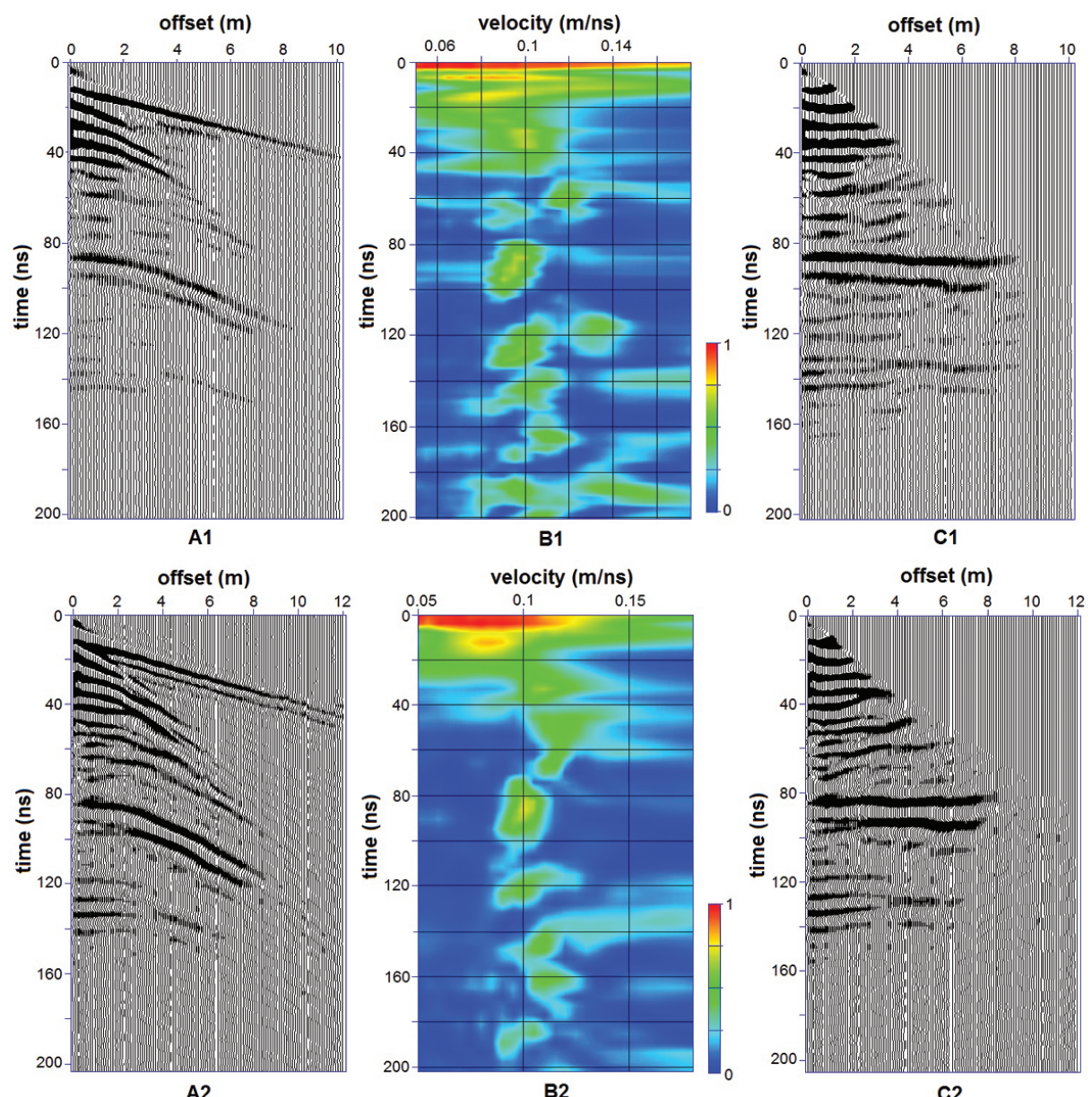

Figure 11 - Radargrams obtained with CMP arrays at the investigated site in March/2006 (A1) and August/2005 (A2), respective semblance panels (B), and radargrams after the normal moveout correction (C). 


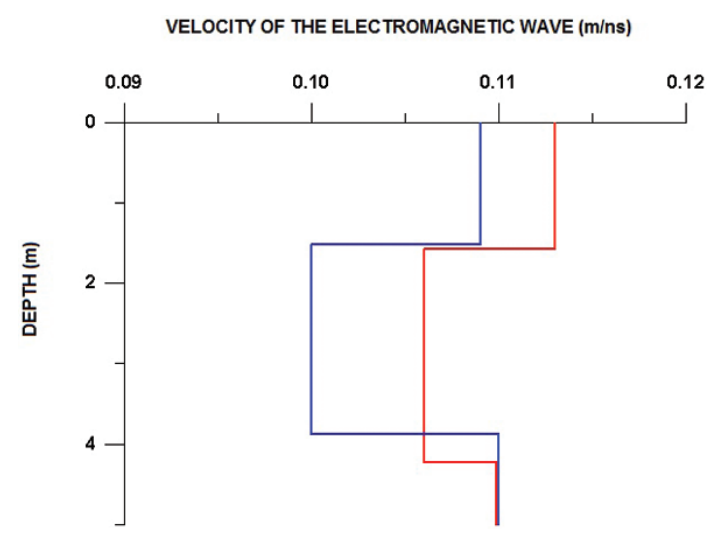

Figure 12 - Velocity profiles for the electromagnetic waves obtained from GPR data (blue line - rainy season; red line - dry season).

the investigated soil, the results encourage to seek site-dependent empiric correlations between the S-waves velocity (Vs) or of the small strain shear modulus $\left(G_{\max }\right)$, determined through the MASW method, and soil strength parameters allowing continuous monitoring of the instability areas.

\section{ACKNOWLEDGMENTS}

The authors gratefully acknowledge the Fundação de Amparo à Pesquisa do Estado de São Paulo (FAPESP), Process 2006/00852-3 and the Conselho Nacional de Desenvolvimento Científico e Tecnológico (CNPq), for the financial support in the accomplishment of this research work.

\section{REFERENCES}

AKI K \& RICHARDS PG. 1980. Quantitative seismology: Theory and methods. v.l: W.H. Freeman and Co., New York, 557 pp.

BARTON N, LIEN R \& LUNDE J. 1974. Engineering classification of rock masses for the design of tunnel support. Rock Mechanics, 6(4): 189-236.

BODET L, ABRAHAM 0 \& CLORENNEC D. 2009. Near-Offset Effects on Rayleigh-Wave Dispersion Measurements: Physical Modeling. Journal of Applied Geophysics, 68(1): 95-103.

CINTRA JCA. 2004. Aplicações da Mecânica dos Solos Não-Saturados - Fundações em Solos Colapsíveis. In: $5^{\circ}$ Simpósio Brasileiro de Solos Não Saturados. São Carlos-SP. Vol. 2, 575-593.

DIKMEN U, ARISOYMO \& AKKAYAI. 2010. Offset and linear spread geometry in the MASW method. Journal of Geophysics and Engineering, 7: 211-222.

FOTI S. 2000. Multi-station Methods for Geotechnical Characterization using Surface Waves. Ph.D. Thesis. Politecnico di Torino, 229 pp.
GIACHETI H L. 1991. Estudo experimental de parâmetros dinâmicos de alguns solos tropicais do Estado de São Paulo. Ph.D. Thesis. Escola de Engenharia de São Carlos, Universidade de São Paulo, 232 pp.

GOFORTH T \& HAYWARD C. 1992. Seismic reflection investigations of a bedrock surface buried under alluvium. Geophysics, 57(9): 1217-1227.

GOOGLE EARTH. 2010. Available on: <http://earth.google.com>. ACcess on: May 30, 2010.

LIMA JÚNIOR SB. 2007. Emprego das ondas Rayleigh visando à caracterização geotécnica de solos superficiais de encosta numa área teste em Ubatuba/SP. M.Sc. Dissertation. Universidade de São Paulo, $81 \mathrm{pp}$.

MARCHIORETO A. 2002. Implementação, testes e avaliação do método SASW. Ph.D. Thesis. Instituto de Geociências, Universidade de São Paulo, 106 pp.

MENDES RM. 2008. Estudo das propriedades geotécnicas de solos residuais não saturados de Ubatuba (SP). Doctorate thesis on Engineering. Escola Politécnica, Universidade de São Paulo, São Paulo, 236 pp.

NAZARIAN S \& STOKOE II KH. 1984. In situ shear wave velocities from spectral analysis of surface waves. In: Proceedings of $8^{\text {th }}$ World Conference on Earthquake Engineering. S. Francisco, Prentice Hall, vol. 3, p. 31-38.

PARK CB, MILLER RD \& XIA J. 1999. Multimodal analysis of high frequency surface wave. In: Proceedings of the Symposium on the Application of Geophysics to Engineering and Environmental Problems (SAGEEP 99), Oakland, CA, March 14-18, p. 115-122.

PRAD0 RL. 1994. 0 ensaio sísmico entre furos ("crosshole") no estudo de maciços terrosos e rochosos. Master dissertation on Geophysics. Instituto Astronômico e Geofísico, Universidade de São Paulo, 123 pp.

RICHART FE, HALL JR \& WOODS RD. 1970. Vibrations of soils and foundations. Prentice Hall, Englewood Cliffs, New Jersey, 432 pp. 
STOKOE KH, WRIGHT SG, BAY JA \& ROESSET JM. 1994. Characterization of geotechnical sites by SASW method. Technical Review: Geophysical Characterization of Sites, ISSMFE Technical Committee 10, Oxford Publishers, New Delhi, 15-25.

STROBBIA C. 2002. Surface Wave Method. Acquisition, processing and inversion. Ph.D. Thesis, Politecnico di Torino, 317 pp.

TURK N \& DEARMAN WR. 1987. Assessment of grounting efficiency in a rock mass in terms of seismic velocities. Bulletin of IAEG $n$. 36, France, p. 101-108.

VARGAS M. 1999. Revisão histórico-conceitual dos escorregamentos da Serra do Mar. Solos \& Rochas, São Paulo, 22(1): 53-83.

WU S, GRAY DH \& RICHART FE. 1984. Capillary effects on dynamic modulus of sands and silts. J. Geotech. Eng., 110(9): 1188-1203.
XIA J, MILLER RD \& PARK CB. 1999. Estimation of near-surface shearwave velocity by inversion of Rayleigh waves. Geophysics, 64(3): 691700.

XU Y, XIA J \& MILLER RD. 2006. Quantitative estimation of minimum offset for multichannel surface-wave survey with actively exciting source. Journal of Applied Geophysics, 59(2): 117-125.

Y00N SS \& RIX GJ. 2009. Near-field effects on array-based surface wave methods with active sources. Journal of Geotechnical and Geoenvironmental Engineering, 135(3): 399-406.

ZHANG SX, CHAN LS \& XIA J. 2004. The selection of field acquisition parameters for dispersion images from multichannel surface wave data. Pure and Applied Geophysics, 161: 1-17.

\section{NOTES ABOUT THE AUTHORS}

Sérgio Bezerra Lima Júnior. M.Sc. in Geophysics (IAG/USP, 2007). B.Sc. in Physics (UFC, 2004) and Geophysics (IAG/USP, 2010). Currently a Geology doctorate student at UFC and researcher at Laboratório de Geofísica de Prospecção e Sensoriamento Remoto (LGPSR) of the Universidade Federal do Ceará.

Renato Luiz Prado. Doctor in Geosciences and Environment (IGCE/UNESP, 2000). M.Sc. in Geophysics (IAG/USP, 1994). B.Sc. in Geology (IGc/USP, 1981). Professor at IAG, Universidade de São Paulo.

Rodolfo Moreda Mendes. Doctor in Geotechnical Engineering (EP/USP, 2008). M.Sc. in Urban Engineering (UFSCar, 2001). Civil Engineer (FEIS-UNESP - Ilha Solteira, 1997). Researcher at Instituto Geológico do Estado de São Paulo. 